\title{
Oxidation processes in zircaloy
}

\author{
D. PÊCHEUR, F. LEFEBVRE and C. LEMAIGNAN
}

CEA/CEN Grenoble, DTP/SECC, 85X, 38041 Grenoble cedex, France

\begin{abstract}
A study by transmission electron microscopy has been made of the incorporation and oxidation of intermetallic precipitates $\mathrm{Zr}(\mathrm{Cr}, \mathrm{Fe})_{2}$ into the uniform oxide layer of Zircaloy-4. The main results are :

- most of the precipitates are incorporated unoxidized into the oxide layer and are later oxidized.

- iron concentration evolves significantly during oxidation, especially before the transition, segregating to the precipitate-matrix interface, occasionally as metallic iron, before being dissolved in the matrix. The behavior of the precipitates during oxidation is discussed in the light of previous work and possible consequences to the oxidation process are considered.
\end{abstract}

\section{Introduction}

Corrosion of zirconium alloys is one of the main limitations to the use of high burn-up fuel rods in light water reactors (L.W.R.) [1]. This oxidation is usually described in two steps, with a transition between a cubic and a linear oxidation rate. It was found that the size, chemical composition and distribution of the intermetallic precipitates $\mathrm{Zr}(\mathrm{Cr}, \mathrm{Fe})_{2}$ in Zircaloy-4 significantly alter the oxidation process.

In this work, an investigation by transmission electron microscopy (TEM) is made of as-fabricated Zircaloy-4 oxide layer. Since neutron irradiation produces major microstructure evolutions such as precipitate amorphization and then dissolution [2,3], we have simulated by ion irradiation these irradiation induced damages. After reporting experimental results, the precipitate oxidation process is discussed and a comparison is made betwen the incorporation and oxidation of crystalline precipitates and of precipitates previously made amorphous by ion and neutron irradiation. Several aspects of this work have been described in detail in an earlier paper, only major aspects are developped here [4].

\section{Experimental Methods}

The material used for this work is standard Zircaloy-4 fully recrystallized, with an additionnal heat treatement at $1055 \mathrm{~K}$ during $50 \mathrm{~h}$ in order to increase precipitate size. Samples were oxidized in static autoclave exposure in $10.3 \mathrm{MPa}$ steam, at $675 \mathrm{~K}$ for 3,40 and 420 days, corresponding to oxide thicknesses of 1,4 and $14 \mu \mathrm{m}$. 


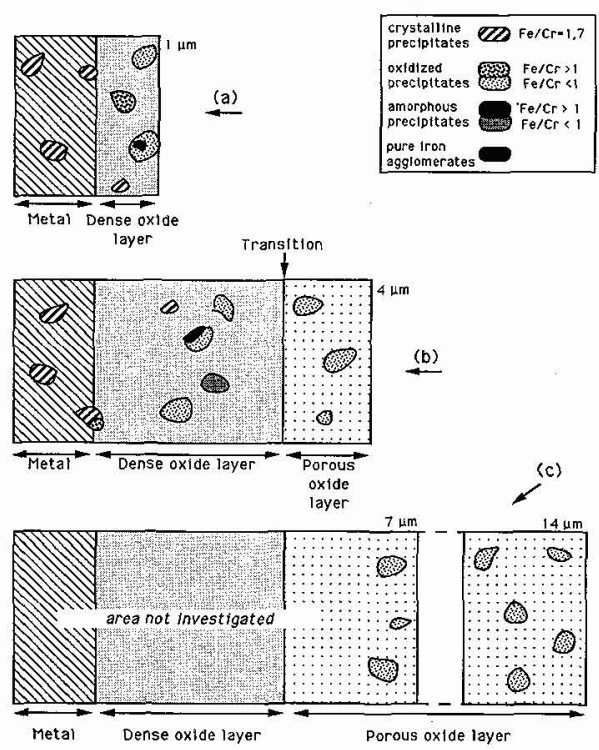

Fig.1. Schematic view of the various oxidation states of the intermetallic precipitates in the $\mathrm{ZrO}_{2}$.

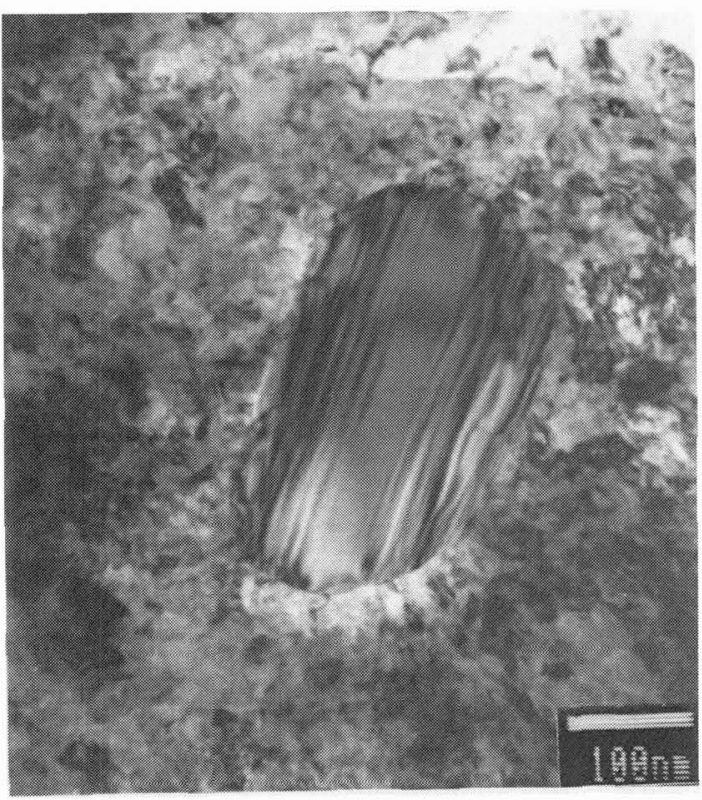

Fig. 2. Unoxidized precipitate located in the bulk of a $1 \mu \mathrm{m}$-thick oxide layer (at about $0.5 \mu \mathrm{m}$ from the metallic interface).
Samples were prepared by standard ion milling procedure with a precise localization procedure with respect to the metal / oxide interface. Observations were carried out in a JEOL 1200 EX STM with energy dispersive X-ray for the $\mathrm{Fe} / \mathrm{Cr}$ ratio.

$1.5 \mathrm{MeV} \mathrm{He}^{+}$ion irradiations were performed in the Van de Graff ion accelerator of the Centre d'Etudes Nucléaires de Grenoble to a damage level of $1.4 \mathrm{dpa}$.

\section{Experimental Results on Reference and} irradiated Zircaloy-4

After the heat treatment, the grain size is ranging between 20 and $130 \mu \mathrm{m} . \mathrm{Zr}(\mathrm{Cr}, \mathrm{Fe})_{2}$ precipitates were of the standard $\mathrm{C} 14$ hcp or the C15 fcc structures, with a typical diameter of about $0.3 \mu \mathrm{m}$, and an $\mathrm{Fe} / \mathrm{Cr}$ ratio of 1.7 .

The general sheme of the oxidation precipitates is given in fig. 1 which shows the precipitate morphology as a function of position in the oxide layer.

- In the middle of the dense oxide layer, both unoxidized precipitates (i.e. original intermetallic precipitates) with the nominal $\mathrm{Fe} / \mathrm{Cr}$ ratio of 1.7 and oxidized precipitates with an $\mathrm{Fe} / \mathrm{Cr}$ ratio decreased to 1.5 are found. One of the unoxidized precipitates is shown in fig.2. The precipitate is tilted so that the stacking fault contrast characteristic of the Laves phases is apparent. All the unoxidized precipitates observed had a diameter less than $0.35 \mu \mathrm{m}$ while the oxidized ones covered the whole size distribution.

For the larger oxide thicknesses, not only original intermetallic and oxidized precipitates are observed but also amorphous precipitates as evidenced by their diffraction pattern (fig.3). These amorphous precipitates found immersed in the oxide layer, have a characteristic nearest neighbor spacing of $2.8 \AA$, as measured from the first ring in the diffraction pattern.

In the outer part of the oxide layer, all 
precipitates are oxidized and their $\mathrm{Fe} / \mathrm{Cr}$ ratio is about 0.5 . No iron precipitation can be observed on the precipitates.

After ion irradiation, the first ring in the amorphous diffraction pattern corresponds to a distance of 2.2 $\AA$, characteristic of the irradiation-made amorphous $\mathrm{Zr}(\mathrm{Cr}, \mathrm{Fe})_{2}$ precipitates. Precipitate chemistry did not change during ion irradiation and amorphization. After three days of oxidation, all the depth affected by the irradiation has been oxidized.

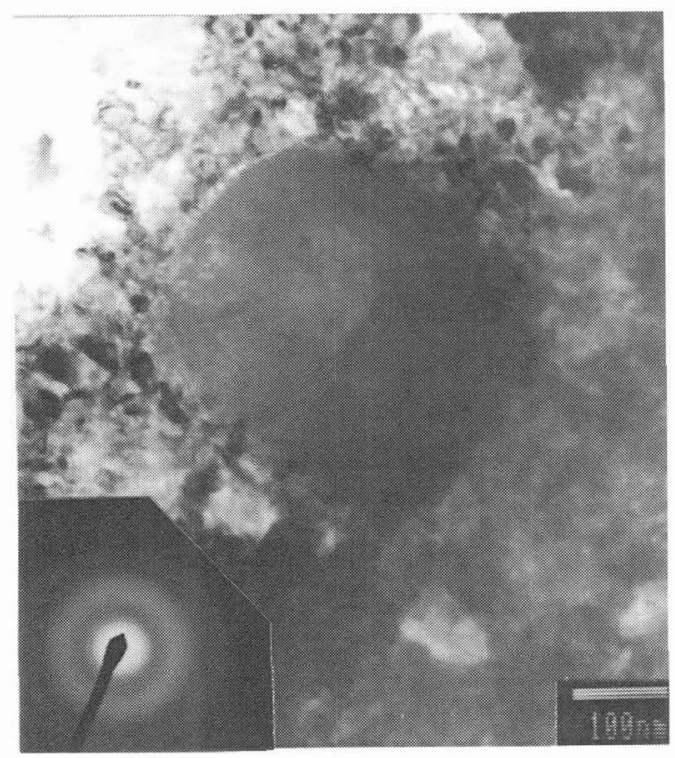

Fig. 3. Amorphous precipitatelocated in the bulk of a 4 $\mu \mathrm{m}$-thick oxide layer. The first ring of the amorphous diffraction pattern corresponds to a first neighbour distance of $2.8 \AA$.
The precipitates that remain amorphous tend to be small $(<450 \mathrm{~nm}$ ) and have an $\mathrm{Fe} / \mathrm{Cr}$ ratio of $\sim 0.5$ in the precipitate bulk. The first ring of their diffraction pattern corresponds to a first neighbour distance of $2.8 \AA$ (from $2.2 \AA$ before corrosion testing).

Oxidized precipitates have a higher $\mathrm{Fe} / \mathrm{Cr}$ ratio (1.5) and tend to be larger and have a morphology consisting of small rod-shaped crystallites gathered into clusters of similar orientation.

All the amorphous precipitates and some of the largest oxidized ones show the presence of iron precipitation at the edges as in the case of non irradiated materials. The morphology of the precipitates oxidized after irradiation is very similar to the case of reference material, except for their original structures.

\section{Discussion}

The oxidation susceptibility of the precipitates, the oxidation state of the constituent elements and the solute element distribution and concentration in the intermetallic precipitates are highly dependent on their position in the oxide layer.

The most important parameters that determine the state of oxidation or solute element depletion of the precipitates appear to be the distance from the metal-oxide interface, roughly equivalent to the residence time in the oxide layer and the distance from the oxide surface roughly equivalent to the oxigen potential.

In this paper, we will only discuss the delayed oxidation of the precipitates with respect to the Zr matrix. The general trend observed is that $\mathrm{Zr}(\mathrm{Fe}, \mathrm{Cr})_{2}$ precipitates are incorporated unoxidized into the oxide layer and are oxidized later. The oxygen potential in the oxide layer is controlled by the boundary conditions of $\mathrm{Zr}$ oxidation on one side and reduction of water on the other side.

With respect to this oxygen potential gradient, an isothermal cut through Ellingham's diagram indicates that among the elements present in Zircaloy-4, zirconium would oxidize first, followed by chromium and then by iron. It is observed in the present work that these broad thermodynamical tendencies are followed. The oxidation of each alloying element is discussed below in terms of the observed oxidation stages: 
It is observed that the zirconium matrix oxidizes first, forming mostly monoclinic zirconia, while the $\mathrm{Zr}(\mathrm{Cr}, \mathrm{Fe})_{2}$ precipitates are still unoxidized.

At a distance between 0.5 and $1 \mathrm{~mm}$ from the metal oxide interface into the oxide layer, the $\mathrm{Zr}(\mathrm{Cr}, \mathrm{Fe})_{2}$ precipitates are observed to be oxidized. Since no diffraction spots corresponding to metallic chromium are seen and no chromium segregation nor dissolution is observed, it is possible that chromium is oxidized.

In those precipitates, a large percentage of tetragonal/cubic $\mathrm{ZrO}_{2}$ is observed. The prevalence of this tetragonal/cubic $\mathrm{ZrO}_{2}$ could be due to a strong stabilization effect : Iron and chromium, some of which being dissolved substitutionally in the cation lattice of $\mathrm{ZrO}_{2}$, would play a major role in such a stabilization.

In the dense oxide, iron segregates and precipitates at the precipitate-oxide interface during the oxidation process. No direct evidence of iron oxidation was found in this work. However, the iron precipitates present in the pre-transition oxide sample are not seen in post-transition ones.

On transition, the oxide becomes porous and the oxygen potential in the oxide layer, at the free surface of the pores, approaches that of reduction of water. The oxidation potential of iron being very close to that of water reduction, it is not surprising that iron oxidizes just after the transition.

In addition to the microcrystalline oxidized precipitates, amorphous precipitates were also found in oxide layers. It is not clear what is the driving force for this amorphization. For other zirconium compounds an hydrogen intake has been proposed as a possible driving force for amorphization [5,6]. Such an hypothesis, in our case, would be consistent with the fact that the first ring in their diffraction pattern corresponding to a nearest neighbour spacing changes to $2.8 \AA$, compared to $2.2 \AA$ measured in $\mathrm{Zr}(\mathrm{Cr}, \mathrm{Fe})_{2}$ precipitates amorphized by electron, ion or neutron irradiations [7]. The reason for such a dilation could then be the absorption of either hydrogen or oxygen into the lattice. In the latter case, there would then be two steps of reaction upon incorporation into the oxide layer: one resulting in an amorphous oxidized precipitate and the other in a microcrystalline oxidized precipitate.

\section{Consequences for Zircaloy-4 Oxidation}

This work indicates that most of the precipitates in Zircaloy oxidize later than the matrix and that upon oxidation, an iron redistribution in the precipitate followed by an iron redissolution in the matrix occurs. Such effects could modify the properties of the oxide in several ways, such as stabilizing the tetragonal/cubic phase, or changing the conduction properties of the oxide. No evidence was seen of an effect of precipitate amorphization on oxidation rates.

One of the reasons for higher corrosion rate of irradiated material could be the larger quantiy of iron and chromium dissolved in the matrix upon neutron irradiation, that will make less $\mathrm{Fe}$ available for $\mathrm{ZrO} 2$ stabilization after incorporation into the zirconia.

\section{Conclusions}

The main experimental observations are the followings:

- Reference intermetallic and irradiated amorphous precipitates oxidize more slowly than the matrix and are embedded unoxidized by the $\mathrm{ZrO}_{2}$ oxidation front.

- The oxide found in the oxidized microcrystalline precipitate is $\mathrm{ZrO}_{2}$ with a higher proportion of tetragonal/cubic zirconia than in the matrix. In the amorphous precipitates the nearest neighbour spacing of 2.8 $\AA$, suggests a possible absorption hydrogen into the precipitate. 
- In the precipitates iron concentration evolves considerably upon both forms of oxidation, especially before the transition. In some cases, a precipitation of metallic bcc iron is observed. After the transition iron precipitates are not observed anymore suggesting that they are dissolved in the $\mathrm{ZrO}_{2}$ matrix.

- The iron redissolution into the matrix seems to be delayed in the case of irradiated precipitates.

\section{References}

I. D. G. Franklin, P. M. Lang, 9th Int. Symp. on Zirconium in the Nuclear Industry, Kobe, Japan, Nov. 1990, ASTM STP 1132, Philadelphia, 1991.

2. M. Griffiths, R. W. Gilbert, G. J. C. Carpenter, J. Nucl. Mater., 150 (1987) 53.

3. W. S. Yang, R. P. Tucker, B. Cheng, R. B. Adamson, J. Nucl. Mater., 138 (1986) 185.

4. D. Pêcheur, F. Lefebvre, A. Motta and C. Lemaignan, J. Nucl. Mat., 189 (1992) 318.

5. W. J. Meng, P. R. Okamoto, L. J. Thompson, B. J. Kestel, L. E. Rehn, Appl. Phys. Lett. 53 (1988) 1820.

6. J. Y. Lee, W. C. Choi, Y. G. Kim; J. Y. Lee, Acta Met. \& Mat. 39 (1991) 1693.

7. A. T. Motta, F. Lefebvre, C. Lemaignan, Proceedings of the 9th Int. Symp. on Zirconium in the Nuclear Industry, Kobe, Japan, November 1990. ASTM STP 1132, Philadelphia, 1991, p. 718. 